PAPER

Related content

\title{
Fast and efficient microwave-assisted synthesis of $\mathrm{CaTiO}_{3}$
}

To cite this article: Sandra de Cássia Pereira et al 2017 Mater. Res. Express 4065014

View the article online for updates and enhancements.

\section{IOP ebooks}

Bringing you innovative digital publishing with leading voices to create your essential collection of books in STEM research. Start exploring the collection - download the first chapter of every title for free. 


\section{Materials Research Express}

\section{PAPER}

\section{Fast and efficient microwave-assisted synthesis of $\mathrm{CaTiO}_{3}$}

RECEIVED

23 March 2017

ACCEPTED FOR PUBLICATION

22 May 2017

PUBLISHED

6 June 2017

\author{
Sandra de Cássia Pereira ${ }^{1}$, Alberthmeiry T de Figueiredo ${ }^{1}$, Cristiano M Barrado ${ }^{1}$, Marcelo H Stoppa ${ }^{2}$, \\ Tatiane $\mathrm{O}$ dos Santos ${ }^{3}$, Fenelon M Pontes ${ }^{4}$ and Elson Longo ${ }^{5}$ \\ 1 Department of Chemistry-UFG Campus Catalão, 75.704-020, Catalão, Brazil \\ 2 Department of Mathematics_-UFG Campus Catalão, 75.704-020, Catalão, Brazil \\ 3 Institute of Physics_-UFG Campus Goiânia, 74.690-900, Goiânia, Brazil \\ 4 Department of Chemistry, Univ. Estadual Paulista, UNESP, 17.033-360, Bauru, Brazil \\ 5 INCTMN, Institute of Chemistry, UNESP, 14.801-970, Araraquara, Brazil \\ E-mail:alberth@ufg.br
}

Keywords: microwave synthesis, $\mathrm{CaTiO}_{3}$, XANES, cube-like structure

Supplementary material for this article is available online

\begin{abstract}
The traditional methods to synthesize nanocrystalline materials are energy-intensive and timeconsuming. This paper describes a fast and simple route to synthesize $\mathrm{CaTiO}_{3}$, which requires just $30 \mathrm{~s}$ of processing in the HTMW system to produce the crystalline orthorhombic phase of CT with a micro-cube-like structure. The product's crystallinity increases along with synthesis time. A correlation is identified between microwave processing time and structural crystallinity.
\end{abstract}

\section{Introduction}

The microwave-assisted synthesis of materials differs fundamentally from conventional synthesis in terms of the heating mechanism involved. In a microwave oven, heat is generated within the volume of the sample by the microwaves interacting with the material. Microwave energy heats material on a molecular level, resulting in uniform heating, whereas conventional heating systems heat material from the outside to the inside, resulting in steep thermal gradients.

The choice of microwave heating in the fabrication of thermoelectric materials has been motivated not only by its lower synthesis cost but also its fast heating rates, which can help preserve the micro- and nanostructure of materials, thereby preventing grain growth. Microwave synthesis is advantageous because microwaves interact directly with ions or molecules in solution and/or with solid phases dispersed in liquid media. In fact, it should be noted that the efficiency in the conversion capacity of microwave energy into thermal energy is governed by the physical variables of loss tangent, relaxation time and penetration depth [1-4].

Calcium titanate $\left(\mathrm{CaTiO}_{3}\right.$ or CT), a versatile material which is one of the major phases in synroc (synthetic rock), is widely used in the immobilization of high level nuclear waste. There are numerous theoretical and experimental studies on the synthesis, characterization and functional performance of CT. One of the most outstanding studies on functional CT involves praseodymium-doped CT. It has long been known as a bright red emitting phosphor characterized by a single and very intense emission peak close to the coordinates of the 'ideal red' color [5-11].

Given the wide range of existing and potential applications, significant research efforts have focused on various synthesis routes for CT and the optimization of its properties [12-17]. Perovskite-structured CT crystals were initially prepared by conventional solid-state reaction, using a stoichiometric ratio of $\mathrm{TiO}_{2}$ and $\mathrm{CaCO}_{3}$ or $\mathrm{CaO}$. This synthesis is difficult because it requires long heat treatments at high temperatures (about $1350{ }^{\circ} \mathrm{C}$ ).

Microwave-assisted heating is a greener approach to synthesize materials in a shorter time (from a few min to several hours) while consuming less energy (a few hundred watts). Recent reports on the hydrothermal microwave (HTMW) synthesis of nanocrystalline titanate oxides [14, 18-21] indicate that the HTMW method is potentially a better route to synthesize crystalline CT powders at low temperatures and high heating rates.

The aim of this work was to synthesize CT by the HTMW method in a short time, using XRD, XANES and morphological analysis to examine the structural order of the synthesized materials. 
Table 1. Data to (121) plane from XRD patterns.

\begin{tabular}{lccr}
\hline Sample & $2 \theta\left(^{\circ}\right)$ & Amplitude & Area \\
\hline CT-30 s & 33.18 & 689 & 203.09 \\
CT-1 min & 33.17 & 1858 & 619.16 \\
CT-2 min & 33.20 & 1881 & 680.68 \\
CT-4 min & 33.18 & 1997 & 681.91 \\
CT-8 min & 33.12 & 2044 & 720.53 \\
CT-600 ${ }^{\circ} \mathrm{C}$ & 33.21 & 2409 & 812.57 \\
\hline
\end{tabular}
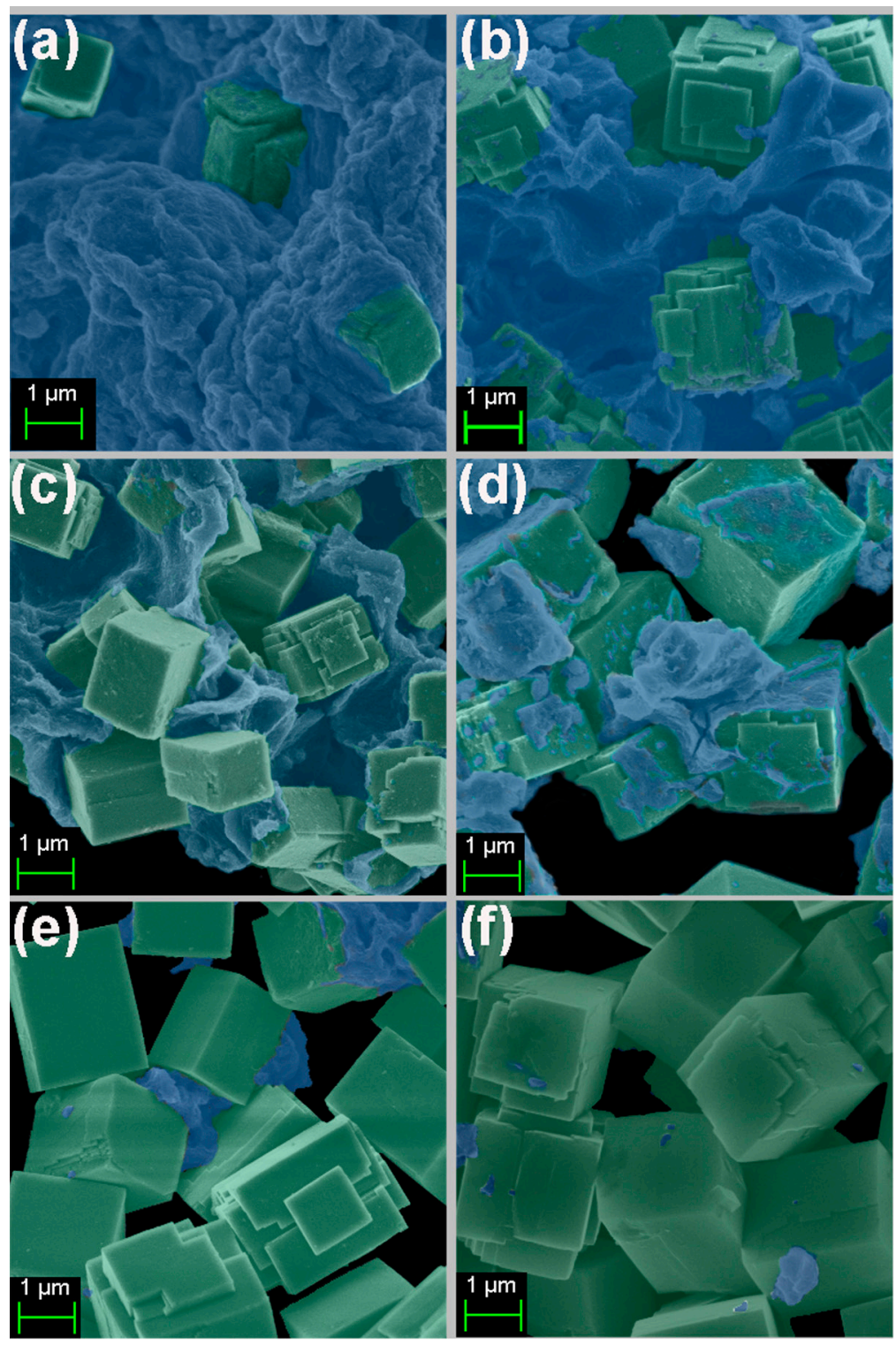

Figure 1. FE-SEM images to CT samples: (a) CT—30 s, (b) CT $-1 \mathrm{~min}$, (c) CT-2 min, (d) CT $-4 \mathrm{~min}$, (e) CT—8 min, and (f) $\mathrm{CT}-600^{\circ} \mathrm{C}$.

\section{Experimental details}

Samples of single crystalline phase $\mathrm{CaTiO}_{3}(\mathrm{CT})$ were synthesized by reacting stoichiometric proportions of $\mathrm{TiO}\left(\mathrm{SO}_{4}\right)$ (Aldrich), $\mathrm{CaCl}_{2} \cdot 2 \mathrm{H}_{2} \mathrm{O}$ (Merck), and $\mathrm{KOH}$ (Merck) by means of microwave-assisted aqueous precipitation [21]. All the chemicals were of higher than $99.9 \%$ purity and were used as received from the vendor. Samples were prepared using the following procedure. First, $\mathrm{TiO}\left(\mathrm{SO}_{4}\right)(0.01 \mathrm{~mol})$ was slowly stirred into $25 \mathrm{ml}$ of deionized water at $398 \mathrm{~K}$ to form $\mathrm{TiO}(\mathrm{OH})_{2}$. Next, a stoichiometric amount of $\mathrm{CaCl}_{2} \cdot 2 \mathrm{H}_{2} \mathrm{O}$ was vigorously stirred into the prepared solution, resulting in a transparent solution. $50 \mathrm{~mL}$ of a solution of $6.0 \mathrm{moll}^{-1} \mathrm{KOH}$, which acts as a mineralizer, was then stirred into the prepared solution. This procedure promoted the co-precipitation of the 

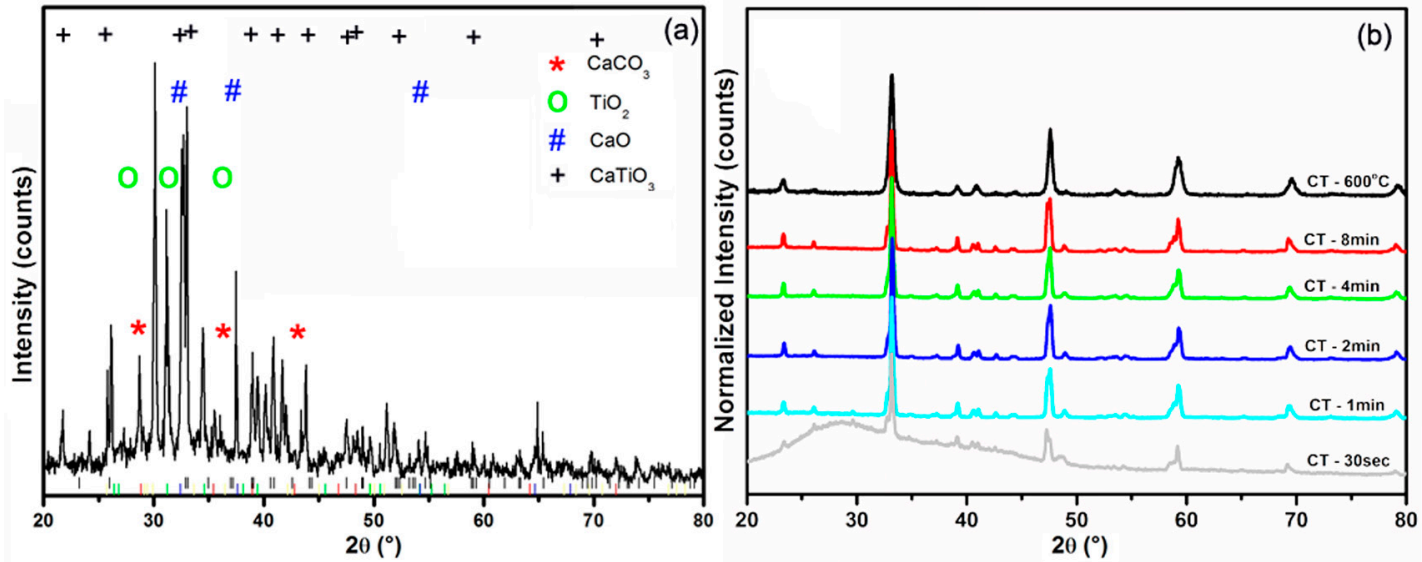

Figure 2. X-ray patterns of CT samples: (a) CT $-\mathrm{NP}$, and (b) CT $-600^{\circ} \mathrm{C}, \mathrm{CT}-8 \mathrm{~min}, \mathrm{CT}-4 \mathrm{~min}, \mathrm{CT}-2 \mathrm{~min}, \mathrm{CT}-1 \mathrm{~min}$, and CT $-30 \mathrm{~s}$.

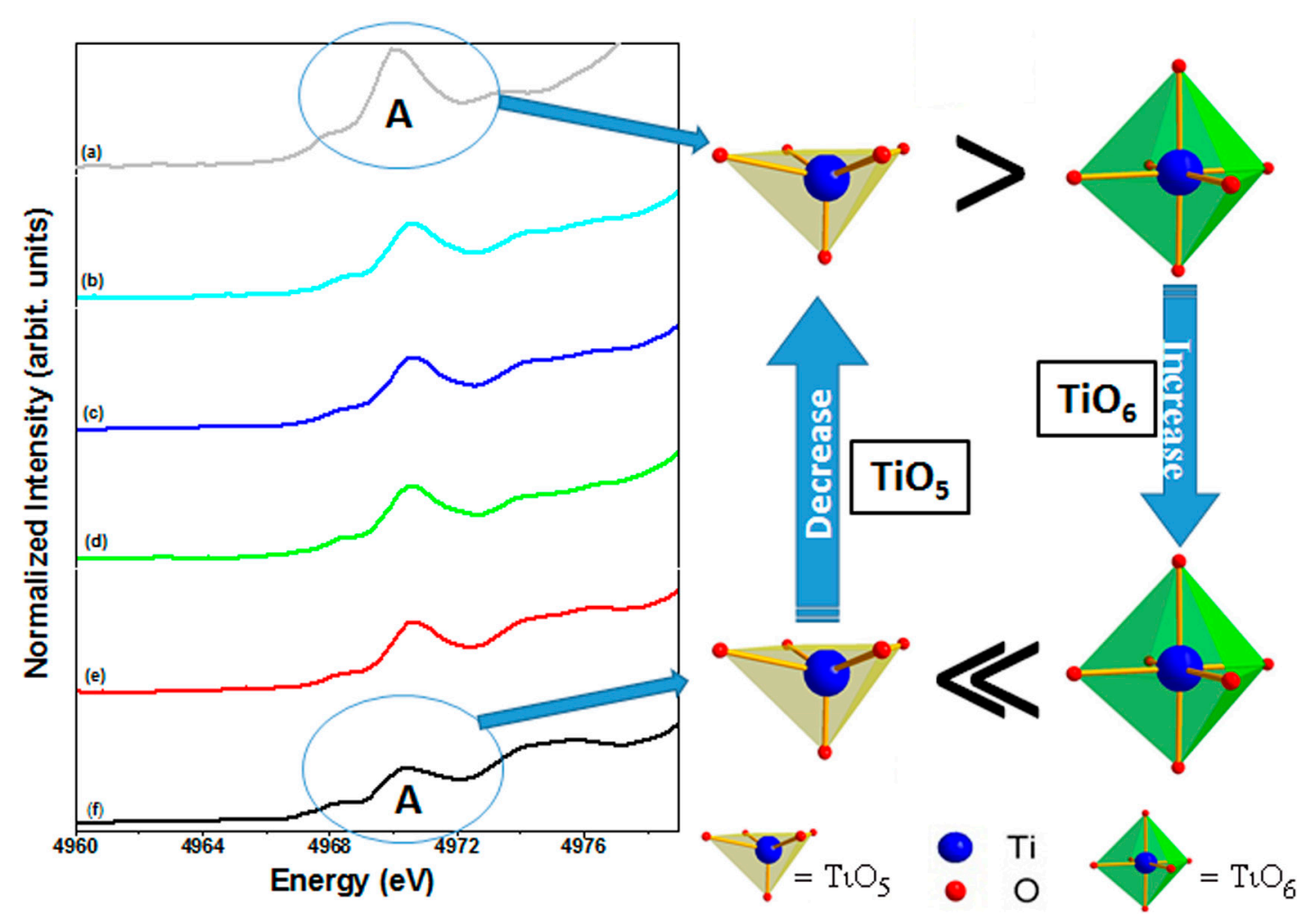

Figure 3. XANES spectra to CT samples: (a) CT $-30 \mathrm{~s}$, (b) CT $-1 \mathrm{~min}$, (c) CT $-2 \mathrm{~min}$, (d) CT $-4 \mathrm{~min}$, (e) CT $-8 \mathrm{~min}$, and (f) $\mathrm{CT}-600^{\circ} \mathrm{C}$

amorphous titanium oxide $\left(\mathrm{TiO}(\mathrm{OH})_{2}\right)$ and calcium $\left(\mathrm{Ca}(\mathrm{OH})_{2}\right)$ hydroxides to form the reaction mixture. This mixture was then poured into a Teflon-lined autoclave, reaching $66 \%$ of its total volume capacity and thus ensuring the maximum pressure efficiency. The autoclave was then sealed and placed in the domestic HTMW system, which operated at $2.45 \mathrm{GHz}$ microwave radiation with a maximum power of $800 \mathrm{~W}$. This mixture was heated at $140{ }^{\circ} \mathrm{C}$ under a nominal heating rate of $140^{\circ} \mathrm{C} \mathrm{min}^{-1}$ by direct interaction of water molecules with microwave radiation, and was left under a constant pressure of $250 \mathrm{KPa}$ for different lengths of time. The autoclave was then allowed to cool naturally to room temperature. The resulting solid product was washed in water until its pH became neutral, and then dried at $60^{\circ} \mathrm{C}$ for $24 \mathrm{~h}$. The HTMW processing times were: $30 \mathrm{~s}$ (CT-30 s), $1 \mathrm{~min}(\mathrm{CT}-1 \mathrm{~min}), 2 \mathrm{~min}$ (CT-2 $\mathrm{min}$ ), $4 \mathrm{~min}(\mathrm{CT}-4 \mathrm{~min}$ ), and $8 \mathrm{~min}(\mathrm{CT}-8 \mathrm{~min})$. Two additional samples were prepared: (i) no HTMW processing (CT-NP), and (ii) $8 \mathrm{~min}$ of HTMW processing plus heat treatment at $600{ }^{\circ} \mathrm{C}$ for $2 \mathrm{~h}\left(\mathrm{CT}-600{ }^{\circ} \mathrm{C}\right)$. All reactions had yields greater than $90 \%$. Table 1 describes the synthesized samples. 


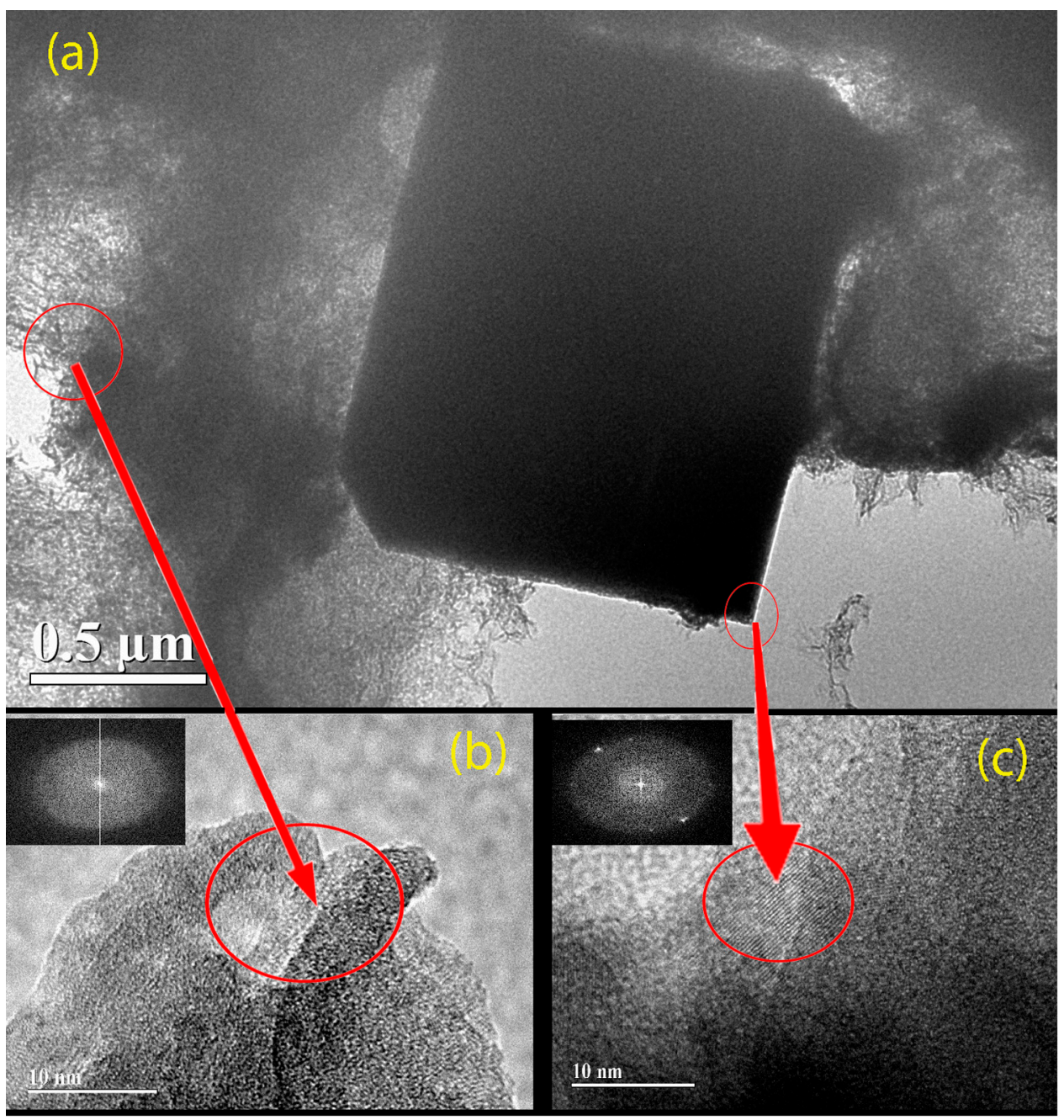

Figure 4. TEM images to CT sample: CT $-2 \mathrm{~min}$.

\section{Results and discussion}

The FEG micrographs of CT samples in figure 1 show a cube-like morphology, which remained unchanged as the synthesis time was increased from 0.5 to $8 \mathrm{~min}$.

The samples obtained in a short processing time presented a few cube-like structures dispersed in a mass of material of amorphous morphology. However, the morphology of the CT particles changed as a function of reaction time. Only a small part of the particles of the CT - 30 s sample showed a cubic morphology, while the remainder exhibited an undefined morphology. However, upon increasing the synthesis time, the morphology became more regular and cubic, indicating surface reorganization instead of other nucleation events. Each nanocube 'docks' with the nearest nanocube, and eventually they become aligned, producing cube-like superstructures [14,21]. Most of the particles of the CT-8 min sample showed a cubic morphology, with only a few displaying an undefined morphology. These results may indicate that the $\mathrm{CT}$ particles underwent dissolution and precipitation under HTMW conditions.

Figure 2(a) shows $\mathrm{x}$-ray diffraction patterns of CT samples before undergoing HTMW processing. Note the peaks corresponding to CT phase, although other phases are also present. It was possible to identify the presence of crystalline phases of $\mathrm{CaCO}_{3}, \mathrm{TiO}_{2}, \mathrm{CaO}$, and $\mathrm{CaTiO}_{3}$.

When the samples were subjected to $\mathrm{HTMW}$ processing, $\mathrm{CaTiO}_{3}$ became the main phase.

In HTMW processing, the microwaves coupled with the rotational barrier of water result in uniform heating of the solution. Thus, the phases present before HTMW processing become solubilized, which enables them to interact and form $\mathrm{CaTiO}_{3}$. The XRD data reveal that $\mathrm{HTMW}$ processing is fundamental for the formation of $\mathrm{CaTiO}_{3}$ in such a short time. Figure 2(b) shows XRD diffractograms of CT samples subjected to HTMW treatment for differentlengths of time. As can be seen, a mere $30 \mathrm{~s}$ sufficed to obtain only CT phase. This led to the formation of the first cube-like structures.

As the processing time increases, so do the number of effective particle collisions, producing irreversibly oriented attachments that provide favorable thermodynamic and kinetic conditions for CT shaping, which is typical of a bottom-up process [1, 4]. Figure 2(b) depicts the XRD pattern of the CT samples after HTMW processing. All the samples presented only the orthorhombic perovskite-type phase (ICDD PDF card no. 22-0153-Pbnm). 


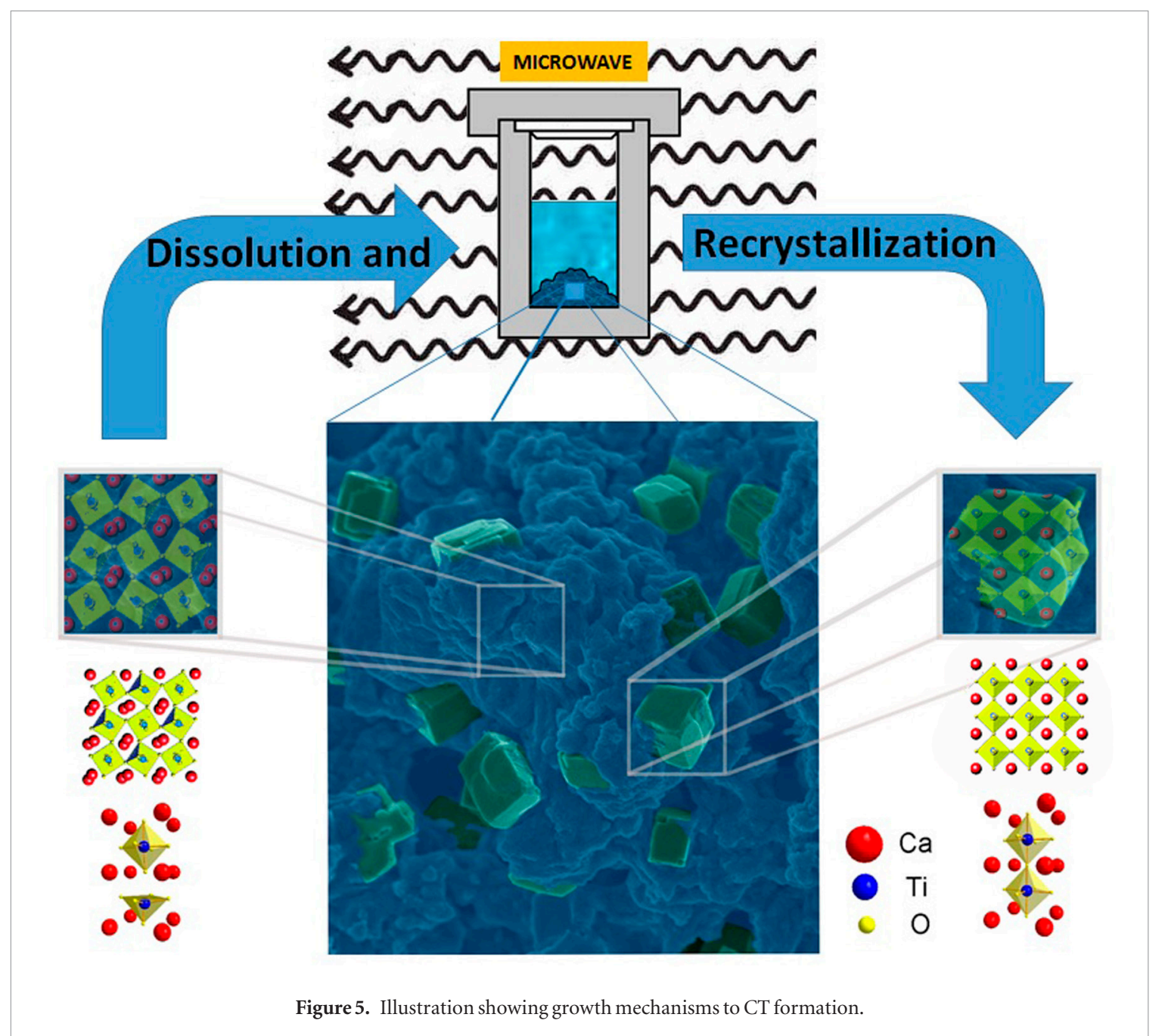

The diffraction peaks differ according to the duration of synthesis. We have created a table that presents some data of the $100 \%$ CT peak ( 121 plane $-2 \theta \cong 33.1^{\circ}$ ). These data confirm the evolution of the crystalline phase.

Note that there is an increase in the intensity and in the area of the $100 \%$ peak. This increase confirms the crystallinity evolution observed in SEM images.

XANES spectra at the Ti K-edge have been shown to be highly sensitive to the symmetry of the titanium site, while providing information about the electronic state and chemical bond of a specific atom. Previous XANES results for titanate powders revealed the coexistence of two types of environments for titanium, namely, a 5-fold $\left(\mathrm{TiO}_{5}\right)$ square-based pyramid and a 6 -fold coordination $\left(\mathrm{TiO}_{6}\right)$ octahedron [22-25]. The crystalline phase of CT is related to the presence of $\mathrm{TiO}_{6}$ clusters, whereas the amorphous phase of CT is related to the presence of $\mathrm{TiO}_{5}$ clusters. Figure 3 shows XANES spectra of the CT samples.

Fully structurally ordered CT- $600^{\circ} \mathrm{C}$ (figure $3(\mathrm{f})$ ) presents only 6-fold or octahedral coordination $\left(\mathrm{TiO}_{6}\right)$, yielding three peaks in the pre-edge region. The pre-edge feature is due to transitions of this mixed $p-d$ orbital. On the other hand, the presence of a intense peak in the pre-edge (peakA) region of these samples when compared with the crystalline ones may also be interpreted as indicating the existence of more than one environment around the titanium atoms [25].

The variation in the height of the pre-edge peak $\mathrm{A}$ is a strong indication of a significant change in the coordination environment of titanium atoms in the CT samples [22, 23]. In figure 3(a), note that the height of the pre-edge A peak shows a maximum for the more disordered sample (CT-30 s) and a minimum for the fully ordered sample $\left(\mathrm{CT}-600^{\circ} \mathrm{C}\right)$, as expected.

Figure 4(a) shows TEM micrographs of the CT samples, which were recorded on a JEOL JEM-2100 transmission electron microscope (TEM) coupled to an energy dispersive spectrometer (EDS).

The CT particles obviously consist of two different types of particles, one with an undefined morphology and the other with a cube-like morphology. Fourier transform of the image of the region with undefined morphology (figure 4(b)) shows a purely amorphous material with only diffuse halo rings but with no sign of diffraction spots. On the other hand, the region with cube-like morphology (figure 4(c)) shows diffraction spots, which is consistent with crystalline material.

The mechanism of formation of CT by the hydrothermal method is discussed in the literature $[13,21,26,27]$. The high $\mathrm{pH}$ level during synthesis helps to stabilize the material. Initially, amorphous CT is formed, with HTMW 
processing triggering the dissolution/recrystallization process, i.e. crystal growth. We believe that the kinetics of formation of the cubes of our material is very fast. The cubes that are formed after the amorphous material dissolves are already large, and no other geometric forms are visible that could confirm the mechanism of formation. However, the formation of the cubes is visible in all the parts of the figure 1 . The cubes that are formed show sides that are still being constructed, as is clearly indicated by the presence of rectangular plates on the faces. At the same time, the amorphous phase gradually decreases, indicating the onset of the mechanism of Ostwald ripening. As the processing time is extended, the cubes become more uniform, without deformed sides. HTMW processing enables the production of crystalline CT with a cube-like morphology (figure 5).

\section{Conclusions}

CT was successfully obtained by the HTMW method. Just $30 \mathrm{~s}$ of processing in the HTMW system sufficed to produce the crystalline orthorhombic phase of CT. This fast synthesis resulted in crystalline and amorphous CT. Increasing the processing time in the HTMW system reduced the amount of amorphous CT while increasing the amount of crystalline CT. The micrographs revealed that the CT obtained by HTMW had a cubic morphology, while the TEM images confirmed that the region with undefined morphology was amorphous. Therefore, the HTMW method can be used for the synthesis of perovskite-structured CT.

\section{Acknowledgments}

The authors thank the Brazilian research funding agencies FAPEG, CAPES and CNPq for their financial support of this work. This work was supported by INCTMN/CNPq, Brazil. The research was partially performed at LNLSNational Laboratory of Synchrotron Light in Campinas, SP, Brazil.

\section{References}

[1] Chu H P, Liu X J, Niu LY, Li C, Gong YY, Li S Q and Sun C Q 2016 Microwave-assisted synthesis of semiconductor nanomaterials for energy storage Curr. Nanosci. 12 317-23

[2] Chen $\mathrm{G} 2015$ Rapid synthesis of rutile $\mathrm{TiO}_{2}$ powders using microwave heating J. Alloys Compd. 651 503-8

[3] Zhu X H and Hang Q M 2013 Microscopical and physical characterization of microwave and microwave-hydrothermal synthesis products Micron 4421-44

[4] Rao K J, Vaidhyanathan B, Ganguli M and Ramakrishnan P A 1999 Synthesis of inorganic solids using microwaves Chem. Mater. $11882-95$

[5] Chen R and Chen D H 2014 Enhanced luminescence properties of $\mathrm{CaTiO}_{3}: \operatorname{Pr} 3+$ phosphor with addition of $\mathrm{SiO}_{2}$ by solid-state reaction Spectroc. Acta A 127 256-60

[6] Kaur J, Dubey V, Parganiha Y, Singh D and Suryanarayana N S 2015 Review of the preparation, characterization, and luminescence properties of $\mathrm{Pr}^{3+}$-doped $\mathrm{CaTiO}_{3}$ phosphors Res. Chem. Intermed. $413597-621$

[7] Yoon S et al 2013 Improved photoluminescence and afterglow of $\mathrm{CaTiO}_{3}: \mathrm{Pr}^{3+}$ by ammonia treatment Opt. Mater. Express $3248-59$

[8] Li Z J, Zhang Y J, Zhang H W and Fu H X 2013 Long-lasting phosphorescence functionalization of mesoporous silica nanospheres by $\mathrm{CaTiO}_{3}: \mathrm{Pr}^{3+}$ for drug delivery Microporous Mesoporous Mater. 176 48-54

[9] Chen R, Song F L, Chen D H and Peng Y H 2009 Improvement of the luminescence properties of CaTiO(3):Pr obtained by modified solid-state reaction Powder Technol. 194252-5

[10] Zhang X M, Zhang J H, Nie Z G, Wang MY, Ren X G and Wang X J 2007 Enhanced red phosphorescence in nanosized CaTiO 3 : $\mathrm{Pr}^{3+}$ phosphors Appl. Phys. Lett. 90151911

[11] Tang W J, Wang K, Bi X H and Chen D H 2007 Synthesis of CaTiO3: Pr,Al phosphors by a peroxide-based route and their photoluminescence properties J. Mater. Sci. 42 9915-9

[12] Zhao HY, Duan Y W and Sun X 2013 Synthesis and characterization of $\mathrm{CaTiO}_{3}$ particles with controlled shape and size New J. Chem. 37 986-91

[13] Yang X F, Fu J X, Jin C J, Chen J A, Liang C L, Wu M M and Zhou W Z 2010 Formation mechanism of CaTiO 3 hollow crystals with different microstructures J. Am. Chem. Soc. 132 14279-87

[14] Moreira M L, Paris E C, do Nascimento G S, Longo V M, Sambrano J R, Mastelaro V R, Bernardi M I B, Andres J, Varela J A and Longo E 2009 Structural and optical properties of $\mathrm{CaTiO}_{3}$ perovskite-based materials obtained by microwave-assisted hydrothermal synthesis: an experimental and theoretical insight Acta Mater. 57 5174-85

[15] Cavalcante L S, Marques V S, Sczancoski J C, Escote M T, Joya M R, Varela J A, Santos M, Pizani P S and Longo E 2008 Synthesis, structural refinement and optical behavior of $\mathrm{CaTiO}_{3}$ powders: a comparative study of processing in different furnaces Chem. Eng. J. $143299-307$

[16] Patil B M, Srinivasa R S and Dharwadkar S R 2007 Synthesis of $\mathrm{CaTiO}_{3}$ from calcium titanyl oxalate hexahydrate (CTO) as precursor employing microwave heating technique Bull. Mater. Sci. 30 225-9

[17] de Figueiredo A T, de Lazaro S, Longo E, Paris E C, Varela J A, Joya M R and Pizani P S 2006 Correlation among order-disorder, electronic levels, and photoluminescence in amorphous CT: Sm Chem. Mater. 18 2904-11

[18] Souza A E, Santos G T A, Silva R A, Moreira M L, Volanti D P, Paris E C, Teixeira S R and Longo E 2012 Morphological and structural changes of $\mathrm{Ca}_{x} \mathrm{Sr}_{1-x} \mathrm{TiO}_{3}$ powders obtained by the microwave-assisted hydrothermal method Int. J. Appl. Ceram. Technol. 9 186-92

[19] Mazzo T M, Moreira M L, Pinatti I M, Picon F C, Leite E R, Rosa I L V, Varela J A, Perazolli L A and Longo E $2010 \mathrm{CaTiO}_{3}:$ Eu $^{3+}$ obtained by microwave assisted hydrothermal method: a photoluminescent approach Opt. Mater. 32 990-7

[20] Chen R and Chen D H 2009 Synthesis by microwave-assisted and luminescence properties of CaTiO(3): $\operatorname{Pr}(3+)$ phosphor J. Alloys Compd. 476 671-4 
[21] Pereira S C, Figueiredo A T, Barrado C M, Stoppa M, Dwivedi Y, Li M S and Longo E 2015 Facile microwave-assisted synthesis of lanthanide doped $\mathrm{CaTiO}_{3}$ nanocrystals J. Braz. Chem. Soc. 26 2339-45

[22] de Figueiredo A T, Longo V M, da Silva R O, Mastelaro V R, Mesquita A, Franco R W A, Varela J A and Longo E 2012 Structural XANES characterization of $\mathrm{Ca}_{0.99} \mathrm{Sm}_{0.01} \mathrm{TiO}_{3}$ perovskite and correlation with photoluminescence emission Chem. Phys. Lett. 544 43-8

[23] Milanez J, de Figueiredo A T, de Lazaro S, Longo V M, Erlo R, Mastelaro V R, Franco R W A, Longo E and Varela J A 2009 The role of oxygen vacancy in the photoluminescence property at room temperature of the CaTiO(3) J. Appl. Phys. 106043526

[24] Jiang N, Su D and Spence J C H 2007 Determination of ti coordination from pre-edge peaks in TiK-edge XANES Phys. Rev. B 76214117

[25] Farges F, Brown G E and Rehr J J 1997 Ti K-edge XANES studies of Ti coordination and disorder in oxide compounds: comparison between theory and experiment Phys. Rev. B 561809

[26] Zhan H Q, Chen Z G, Zhuang J L, Yang X F, Wu Q L, Jiang X P, Liang C L, Wu M M and Zou J 2015 Correlation between multiple growth stages and photocatalysis of $\mathrm{SrTiO}_{3}$ nanocrystals J. Phys. Chem. C 1193530-7

[27] Huang Y J, Chiu H T and Lee CY 2009 Growth of $\mathrm{CaTiO}_{3}$ dendrites and rectangular prisms through a wet chemical method CrystEngComm 11 1904-9 